\title{
Transcriptional regulatory circuits controlling muscle fiber type switching
}

\author{
LIU Jing, LIANG XiJun \& GAN ZhenJi* \\ MOE Key Laboratory of Model Animal for Disease Study, Model Animal Research Center, Nanjing University, Nanjing 210061, China
}

Received August 4, 2014; accepted December 17, 2014; published online March 19, 2015

\begin{abstract}
Skeletal muscle fitness plays vital roles in human health and disease and is determined by developmental as well as physiological inputs. These inputs control and coordinate muscle fiber programs, including capacity for fuel burning, mitochondrial ATP production, and contraction. Recent studies have demonstrated crucial roles for nuclear receptors and their co-activators, and microRNAs (miRNAs) in the regulation of skeletal muscle energy metabolism and fiber type determination. In this review, we present recent progress in the study of nuclear receptor signaling and miRNA networks in muscle fiber type switching. We also discuss the therapeutic potential of nuclear receptors and miRNAs in disease states that are associated with loss of muscle fitness.
\end{abstract}

\section{fiber type switching, gene regulation, muscle, nuclear receptor, microRNA}

Citation: Liu J, Liang XJ, Gan ZJ. Transcriptional regulatory circuits controlling muscle fiber type switching. Sci China Life Sci, 2015, 58: 321-327, doi: 10.1007/s11427-015-4833-4

Skeletal muscle is the biggest organ in the human body; it comprises $\sim 40 \%$ of total body mass [1,2]. As one of the most metabolically demanding tissues that has very active lipid and glucose metabolism, skeletal muscle can account for $\sim 80 \%$ of insulin-stimulated glucose disposal [3-5]. Skeletal muscle fitness plays important roles in human health and disease. Skeletal muscle fitness is determined by developmental as well as physiological inputs. These inputs control and coordinate muscle fiber programs, including fuel burning, mitochondrial ATP production, and contraction. Exercise is well known to be effective in improving muscle fitness by promoting favorable metabolic and structural adaptations [3-5]. Exercise training enhances muscle endurance and performance by augmenting the capacity of mitochondria to burn glucose and fatty acids and by increasing the proportion of slow oxidative fibers and blood supply [3-5]. Conversely, skeletal muscle dysfunction, in-

*Corresponding author (email: ganzj@nju.edu.cn) cluding fiber type switching and decreased oxidative capacity, is a common consequence of physical inactivity, contributing to the progression of many chronic illness, including obesity, diabetes, muscular diseases and aging [2,3,5].

Skeletal muscle is a bundle of muscle fibers. Muscle fibers can be generally classified into oxidative slow-twitch and glycolytic fast-twitch myofibers. Based on myosin isoform expression, muscle in rodents can also be classified into Type I, Type IIa, Type IIx and Type IIb $[1,2,5,6]$ (Figure 1). Type I and IIa fibers are characterized by high endurance and are mitochondria-rich (red), relying largely on mitochondrial oxidative metabolism for ATP production $[2,5,6]$. In contrast, Type IIb fibers generally have low endurance and less mitochondria, and are mainly reliant on glycolytic metabolism for energy production [2,5,6]. An intermediate IIx fiber type has also been defined in rodents, but not in human. How the slow twitch fiber is linked to high metabolic capacity is unclear.

Skeletal muscle exhibits remarkable plasticity, in response 


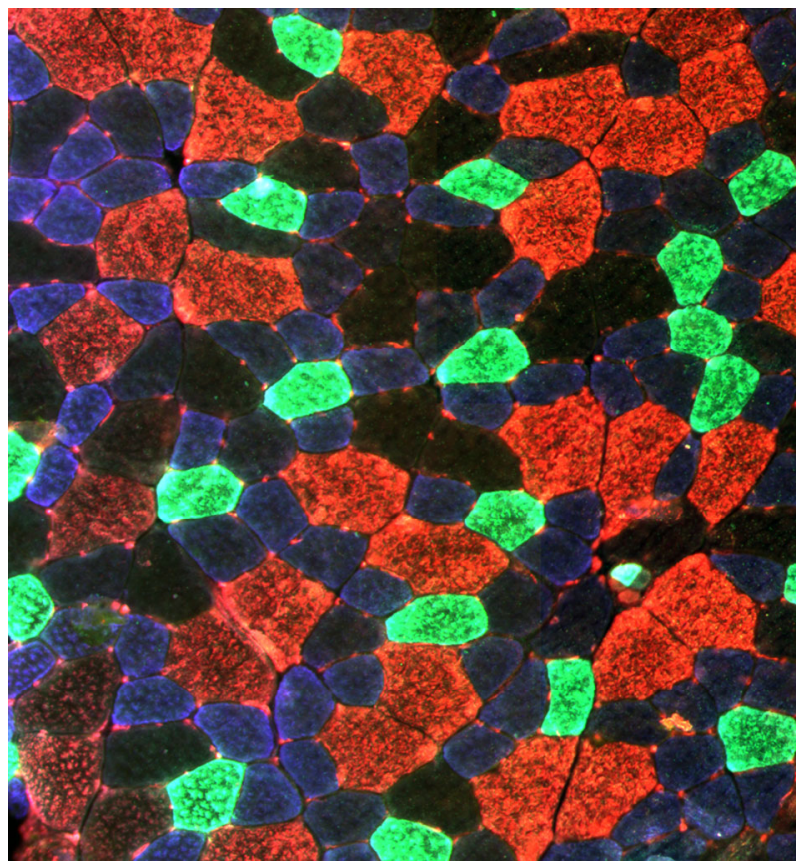

Figure 1 Skeletal muscle fiber types. Muscle fiber typing by immunofluorescence staining of gastrocnemius muscle from 3-month-old C57BL/ $6 \mathrm{~J}$ mice. MHC1 (green), MHC2a (blue), MHC2b (red), and MHC2x (unstained).

to a variety of external stimulations; it undergoes extensive reprogramming to meet its energy and contraction demands. One of the best examples of this reprogramming is fiber type switching. Endurance exercise training results in an increased proportion of slow-twitch Type I and Type IIa fibers. Exercise training also increases the mitochondrial mass, which, in turn, increases capacity for oxidation of fat and glucose, and for exercise [3-5]. Conversely, reduced physical activity, such as occurs in chronic diseases states, results in a reduced proportion of Type I and Type IIa fibers [3-5]. Importantly, whole body insulin sensitivity and insulin-stimulated glucose uptake is significantly positively correlated with the proportion of slow-twitch muscle fibers $[3,4,7]$. The gene regulatory circuitry that controls muscle fiber type switching has been partially delineated over the past two decades. In addition to the widely accepted calcineurin/NFAT and the HDAC/MEF2 signaling pathways $[8,9]$, it has recently been shown that nuclear receptor signaling and miRNAs also play crucial roles in the regulation of skeletal muscle energy metabolism and fiber type switching.

\section{The PPAR subfamily of nuclear receptors}

Nuclear receptors are a class of transcription factor that can sense hormones (also termed ligands) and that regulate gene expression in response to external stimuli [10-13]. The peroxisome proliferator-activated receptor (PPAR) subfamily of nuclear receptors comprises three members, PPAR $\alpha$, $\operatorname{PPAR} \beta / \delta$, and PPAR $\gamma$ [10-13]. PPAR $\alpha$ is highly expressed in oxidative tissues such as skeletal muscle, liver and heart $[14,15]$. PPAR $\beta / \delta$ is ubiquitously expressed, with relatively high levels of expression in heart, skeletal muscle and brain [16], while PPAR $\gamma$ is adipose-specific and plays a vital role in adipocyte differentiation and fat storage [10,13]. PPARs form heterodimers with retinoid $X$ receptors (RXRs) and bind to the PPAR response element (PPRE) in target gene promoters $[10,17]$. The activity of PPARs can be modulated by its expression levels, the availability of endogenous ligands, and its co-activators [10,13], as described below. Both gain of function and loss of function studies have demonstrated that PPAR $\alpha$ and PPAR $\beta / \delta$ are key regulators of skeletal muscle energy metabolism and fiber type switching.

PPAR $\alpha$ regulates the expression of genes involved in almost every step of fatty acid metabolism in skeletal muscle $[14,15,18]$. Transgenic mice, in which PPAR $\alpha$ is overexpressed specifically in skeletal muscle (MCK-PPAR $\alpha$ mice), have up-regulated expression of genes involved in fatty acid uptake, oxidation, storage, and mitochondrial oxidative phosphorylation, and the mice have high fatty acid oxidation (FAO) rates and are resistant to high-fat-diet induced obesity [18]. Interestingly, MCK-PPAR $\alpha$ mice develop insulin resistance and glucose intolerance, and are able to run significant shorter distances than controls $[18,19]$. Gene expression profiling demonstrated that the expression of genes involved in glucose uptake and glycolysis was decreased in MCK-PPAR $\alpha$ mice $[18,19]$. Even more surprisingly, fiber typing analysis demonstrated a dramatic reduction in Type I fibers in MCK-PPAR $\alpha$ muscle compared to control littermates [20]. In contrast to the gain of function models, PPAR $\alpha$-deficient mice display decreased muscle FAO rates, and exhibit a mild age-associated cardiac fibrosis and an inability to compensate for increased cardiac workloads [21], indicating that PPAR $\alpha$ is necessary for the heart's high capacity for burning fat. Moreover, PPAR $\alpha$-deficient muscle induces a shift in muscle fiber type proportion towards a slow oxidative type [20]. Taken together, although PPAR $\alpha$ can potently activate mitochondrial FAO, it is also a repressor of slow-oxidative muscle fiber gene expression; therefore, its activity needs to be finely regulated in skeletal muscle.

$\mathrm{PPAR} \beta / \delta$ can also potently activate the expression of genes involved in fatty acid metabolism in skeletal muscle [19,20,22-25]. Surprisingly, transgenic mice, in which $\mathrm{PPAR} \beta / \delta$ is over-expressed specifically in skeletal muscle, have a phenotype that is remarkably different from that of the muscle-specific PPAR $\alpha$ transgenic mice, despite the fact that both lines have increased capacity for mitochondrial FAO [19,20,23-25]. Three independent studies have demonstrated that over-expression of $\mathrm{PPAR} \beta / \delta$ in skeletal muscle induces a slow-oxidative muscle fiber program [20,24,25]. Mice over-expressing a constitutively active 
form of $\mathrm{PPAR} \beta / \delta$ in skeletal muscle have increased endurance of more than $100 \%$ [25]. Consistently, the number of Type I muscle fibers is increased in the transgenic muscle and the mice are resistant to high-fat-diet induced obesity and have improved glucose tolerance [25]. Mice expressing a native $\mathrm{PPAR} \beta / \delta$ protein also induce high FAO gene expression, and have more oxidative fibers than controls [20,24]. The MCK-PPAR $\beta / \delta$ mice exhibit many of the metabolic benefits of exercise, despite the absence of exercise training, including increased muscle glucose utilization $[19,20]$. For example, the MCK-PPAR $\beta / \delta$ mice have superb exercise capacity on a motorized treadmill; interestingly, this phenotype is more apparent with a high-intensity exercise protocol. Muscle glycogen levels are also significantly increased in the MCK-PPAR $\beta / \delta$ mice [19]. The most striking phenotype is that $\mathrm{PPAR} \beta / \delta$ drives a complete shift towards a type I oxidative muscle fiber type program. Fiber type staining demonstrated a $100 \%$ increase in Type I fibers in MCK-PPAR $\beta / \delta$ soleus muscle [20]. Analysis of transcripts encoding the myosin heavy chain (MHC) isoforms revealed an increased expression of Type I MHC in MCK-PPAR $\beta / \delta$ muscle, whereas the levels of MHC Type IIa, IIx, and IIb mRNAs were markedly suppressed [20]. Moreover, several slow-twitch troponin genes are induced and fast twitch troponin genes suppressed in MCK$\mathrm{PPAR} \beta / \delta$ muscle [20]. In contrast to the muscle-specific $\operatorname{PPAR} \beta / \delta$ transgenic mice, skeletal muscle-specific $\operatorname{PPAR} \beta / \delta$-null mice exhibit a shift towards a greater proportion of glycolytic-type muscle fibers. These mice have decreased expression of FAO genes. On a high-fat-diet, the mice gain more weight and are more prone than controls to developing insulin resistance and glucose intolerance [26]. Taken together, these data demonstrate that PPAR $\beta / \delta$ is necessary for both muscle FAO and the Type I fiber program, and that activation of PPAR $\beta / \delta$ in skeletal muscle can coordinately regulate muscle energy metabolism and fiber type switching to improve muscle fitness.

\section{The PGC-1 co-activator}

The discovery of PPAR $\gamma$ coactivator- $1 \alpha$ (PGC-1 $\alpha)$ as a coactivator of PPAR $\gamma$ in brown adipose tissue by the laboratory of Bruce Speigelman has provided significant insight into how PPARs and other nuclear receptors are regulated in response to the physiological and nutritional states of skeletal muscle [27-32]. PGC- $1 \alpha$ is a member of a family of transcriptional coactivators that includes PGC- $1 \alpha$, PGC-1 $\beta$, and the PGC-1-related coactivator (PRC) [29-32]. PGC-1 $\beta$ has significant homology with PGC- $1 \alpha$ and shares many of its functions in skeletal muscle [33,34]. PGC- $1 \alpha$ co-activates a number of transcription factors including the PPAR and estrogen-related receptor (ERR) nuclear recep- ors, the nuclear respiratory factors $1 / 2$ (NRF1/NRF2) and MEF2 [29-32,35]. PGC-1 $\alpha$ directly interacts with its target transcription factors, serving to recruit molecules that mediate chromatin remodeling via histone acetyltransferase (HAT) activity, and by recruiting components of the transcriptional machinery, such as RNA polymerase II to activate gene transcription [29-32]. PGC-1 $\alpha$ expression can be induced by a variety of physiological stimuli, such as cold exposure, fasting, and exercise [27-32,36-38]. Thus, PGC- $1 \alpha$ can orchestrate the activity of multiple transcription factors in response to a variety of external stimuli to control metabolic and structural adaptations in muscle.

Extensive studies have supported a critical role for PGC-1 coactivators in skeletal muscle [39-48]. The first evidence came with observations in animal models and humans that PGC-1 $\alpha$ gene expression is induced in skeletal muscle in physiological conditions that require increased energy expenditure, such as exercise [36,40,41]. Gain-offunction studies performed in cultured myocytes have shown that PGC- $1 \alpha$ is capable of activating virtually all aspects of mitochondrial biogenesis in muscle cells, including increased expression of oxidative phosphorylation and FAO genes, increased number of mitochondria, and enhanced mitochondrial respiratory capacity [42]. Transgenic systems and gene knockout (KO) approaches have been used to define the physiological roles of PGC-1 coactivators in skeletal muscle. Two independent studies have shown that over-expression of PGC- $1 \alpha$ in skeletal muscle induces an oxidative fiber-type transformation [43,44]. Forced over-expression of PGC- $1 \alpha$ under a muscle specific MCK promoter increases muscle oxidative capacity and the proportions of Type I and IIa fibers [43]. A skeletal muscle-specific, tetracycline-regulated PGC- $1 \alpha$ over-expression system has also been employed to mimic the induction of PGC-1 $\alpha$ known to occur post-exercise. Induced expression of PGC- $1 \alpha$ in adult skeletal muscle triggered mitochondrial biogenesis, increased "red" muscle, and expanded muscle glycogen stores, key features of exercise training [44]. Interestingly, a short form of PGC-1 $\alpha$ (PGC-1 $\alpha 4)$ has been recently shown to induce muscle hypertrophy [49], while full length PGC-1 $\alpha$ was shown to regulate kynurenine metabolism and to protect mice from stress-induced depression [50]. Taken together, the gain of function study results suggest that induction of PGC-1 $\alpha$, which is known to occur following exercise, drives a trained skeletal muscle phenotype.

Mice with targeted ablation of the genes encoding either PGC- $1 \alpha$ or PGC-1 $\beta$ have a minimal phenotype until they are challenged with a physiological stress that increases demand for ATP production [33,34,45-48]. For example, PGC-1 $\alpha \mathrm{KO}$ mice have reduced exercise capacity on a treadmill compared to wild-type controls [47,48], while combined deficiency of PGC- $1 \alpha$ and PGC- $1 \beta$ in skeletal muscle results in a dramatic exercise performance deficit 
related to mitochondrial dysfunction [39]. The exercise phenotype of muscle-specific PGC- $1 \alpha / \beta$ double-KO mice is associated with a marked decrease in muscle respiratory capacity and derangement of mitochondrial structure [39]. In addition, the conventional PGC- $1 \alpha / \beta$ double-KO mice die soon after birth with heart failure [51]. Studies of PGC- $1 \alpha / \beta$ double-KO heart sections by electron microscopy revealed that the normal perinatal mitochondrial biogenic response was completely absent [51]. Thus, these results of phenotypic analyses of the PGC- $1 \alpha$ - and PGC- $1 \beta$ deficient mice have shown that both coactivators are necessary for mitochondrial respiratory function in skeletal muscle and heart. However, despite severe mitochondrial abnormalities, the proportion of Type I and IIa fibers was not diminished in PGC- $1 \alpha / \beta$ double-KO muscle [39], suggesting that PGC- $1 \alpha / \beta$ deficiency triggers an adaptive reprogramming in skeletal muscle. These results support a surprising conclusion that the PGC-1 coactivators are dispensable for fundamental fiber type determination. Given that PGC- $1 \alpha$ is induced by exercise training, it's still very likely that the induction of PGC- $1 \alpha$ could have a booster function on muscle fiber type switching via its coactivating effects on downstream effecters such as PPAR $\beta / \delta$.

\section{Role of miRNAs in skeletal muscle fiber type determination}

The recent breakthrough discovery of miRNAs as key players of gene regulation has unveiled a new dimension in the control of gene expression [52-57]. miRNAs are a family of small RNA molecules, usually 22 nucleotides long, that were first identified in C. elegans in the early 1990s [58,59]. Since then, miRNAs have been discovered in virtually all plants and mammals [60-62]. Many miRNAs are encoded in the introns of host genes, indicating that they are co-regulated with their host genes. miRNAs are transcribed by RNA polymerase II and after processing by the RNase III enzyme, Drosha, pre-miRNAs are exported to the cytoplasm to be further processed by Dicer [52,55]. Mature miRNAs are incorporated into the RNA-induced silencing complex (RISC), where they bind to their mRNA targets $[52,55,63,64]$. miRNAs can regulate gene expression either through translational repression or direct gene silencing $[52,55,64]$. Interestingly, miRNAs usually modulate a class of mRNA targets that share the same function, thereby controlling complex biological processes.

Evidence is emerging that gene regulatory programs involved in skeletal muscle biology involve miRNAs [53,54,56,65-67]. Several miRNAs, named "MyomiRs", have been shown by Eric Olson's laboratory, to be involved in muscle fiber type programs [65]. Specifically, miR-208b, which is encoded within a type I MHC gene (Myh7), and miR-499, which is encoded within another type I MHC gene (Myh7b), have been shown to drive a slow-twitch fiber program by down-regulating transcriptional repressors that suppress slow-twitch contractile protein gene expression $[65,68]$. The 3'-UTRs of Sox6 and PurB contain conserved target sites for both miR-499 and miR-208b, each of which has been reported to repress Type I marker expression $[65,68,69]$. In addition, gain-of-function and loss-offunction studies in mice have identified an important role for Sox6 in muscle development, fiber type specification, and muscle performance [70-72].

Interestingly, muscle-specific miR-499 transgenic mice run over $50 \%$ longer than wild-type littermates when subjected to a regimen of forced treadmill running [65], indicating an endurance exercise training phenotype in these mice. Moreover, the miR-499 transgenic background completely reverses the exercise performance deficit of MCK-PPAR $\alpha$ mice (the "couch potato" mouse) [20], further supporting a dominant role of miR-499 in muscle physiology. Importantly, miR-499 is relevant in humans. The expression levels of miR-499 are significantly increased in human muscle biopsies from trained athletes compared to sedentary controls [20]. In addition, there is a significant positive correlation between the expression of miR-499 and Type I fiber \%, ATPmax, and $\mathrm{VO}_{2} \max$ in humans [20]. Taken together, these results demonstrate that miR-499 is linked to both the Type I muscle program and to metabolic capacity in humans, providing an important translational relevance.

\section{Cross talk between nuclear receptor signaling and miRNA networks}

Accumulating evidence suggests that there is a cross talk between nuclear receptor signaling and miRNA networks. An interesting connection between PPARs and miRNAs has been discovered in a miRNA expression profiling study with RNA isolated from MCK-PPARs mice [20]. Consistent with the strikingly different phenotypes between the MCK-PPAR $\alpha$ and MCK-PPAR $\beta$ mice, the miRNA expression patterns were remarkably different among the MCKPPARs lines and a subset of miRNAs exhibited reciprocal regulation [20]. For example, levels of miR-208b and miR-499 are significantly increased in MCK-PPAR $\beta / \delta$ muscle but dramatically reduced in MCK-PPAR $\alpha$ muscle [20]. Gain- and loss-of-function studies in primary skeletal muscle cells have demonstrated that PPAR $\alpha$ and PPAR $\beta / \delta$ have opposing roles in the regulation of the Type I fiber program through this miR-499/208b circuit [20]. These results support a model in which PPAR signaling is upstream of $\mathrm{miR}-208 \mathrm{~b} / \mathrm{miR}-499$ and that PPAR $\beta / \delta$ activates, while PPAR $\alpha$ suppresses, the miRNA circuit in muscle.

Interestingly, no consensus PPAR binding sites have been identified in the miR-499/208b promoters. However, 
highly conserved sites for another nuclear receptor, ERR, were identified in both miRNA promoters [20]. ERR $\gamma$ has been shown to promote the Type I fiber program in skeletal muscle [73]. ERR $\gamma$ is suggested to bridge the gap between $\mathrm{PPAR} \beta / \delta$ and the increase in miR-499/208b expression given that levels of ERR $\gamma$ protein were increased in MCK-PPAR $\beta / \delta$ muscle [20]. Moreover, chromatin immunoprecipitation (ChIP) of the miR-499/208b promoters demonstrated that ERR $\gamma$ occupies the region containing the proposed ERR response elements [20]. As expected, levels of miR-499 and miR-208b are dramatically reduced in the ERR $\beta / \gamma$ double KO muscle [20]. Therefore, ERR $\gamma$ serves a critical role in the Type I fiber program by directly activating transcription of miRNA genes via a highly conserved ERR response element. It is very likely that PGC- 1 could have a booster function on this mechanism via its coactivating effects on ERR $\gamma$ and PPAR $\beta / \delta$.

In contrast to PPAR $\beta / \delta$ and ERR $\gamma, \operatorname{PPAR} \alpha$ exerts a repression effect on miR-499 and miR-208b [20]. Interestingly, this effect seams independent of exogenously added PPAR $\alpha$ ligand and promoter mapping indicates that PPAR $\alpha$ suppresses miR-208b promoter activity through the proximal promoter region [20].

\section{Conclusion and perspectives}

It is clear that a sedentary life style is a major risk factor for many chronic diseases and that chronic diseases, such as obesity, diabetes, and muscular diseases, are associated with decreased muscle fitness [2,3,5]. Exercise is well known to enhance muscle fitness. Genetically modified mouse models have demonstrated that there is a nuclear receptor-miRNA circuit that orchestrates programs controlling muscle energy metabolism and fiber type (Figure 2): (i) PGC-1 $\alpha /$ PPAR $\beta /$ $\delta / E R R \gamma$ signaling can drive a trained muscle fiber program; (ii) surprisingly, the closely-related nuclear receptors, $\operatorname{PPAR} \beta / \delta$ and PPAR $\alpha$ exert opposing actions upon fiber type programs through a muscle miRNA network; (iii) $\mathrm{PPAR} \beta / \delta$ activates ERR $\gamma$ which drives the miR-208b/499 circuit and, thus, the Type I fiber program; (iv) studies of human muscle confirmed that this circuit links control of muscle fiber type with metabolic energy capacity. This new information has provided important insight into the role of nuclear receptor signaling and miRNAs networks in muscle fiber type switching.

Given the recent exciting evidence that the expression of ERR $\gamma$ and miR-499 are linked to human fitness [20], the nuclear receptor/miRNA regulatory circuit shows promise as a therapeutic target aimed at enhancing muscle fitness in a variety of chronic disease states that are associated with loss of muscle fitness, including but not limited to, obesity, diabetes, muscular disease, and aging [74]. It will be important to fully define the downstream targets of the nuclear

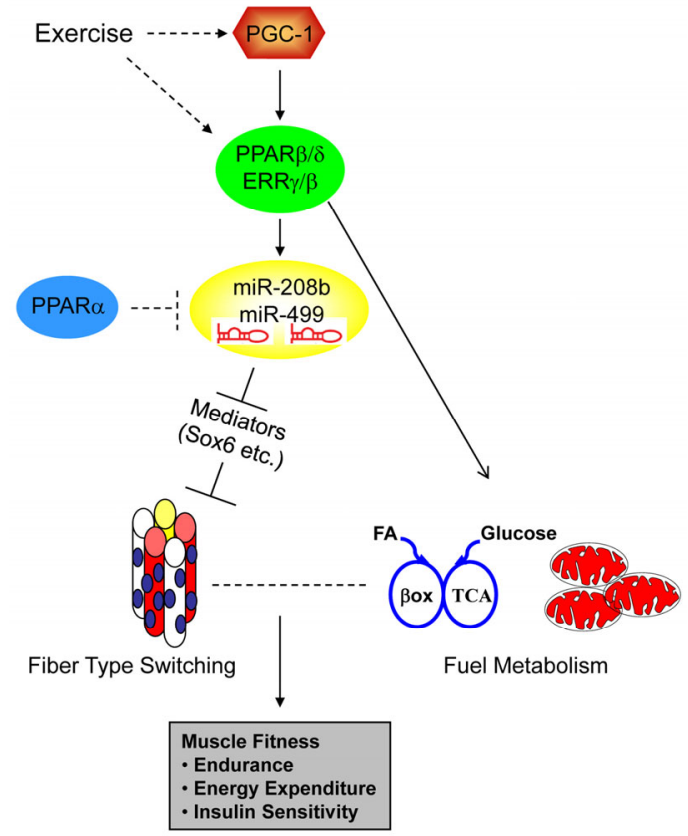

Figure 2 (color online) Model of nuclear receptor signaling and a miRNA network in the control of muscle fiber type switching. The schematic depicts a proposed model for a nuclear receptor-miRNA circuit that controls the muscle Type I fiber program. PPAR $\beta / \delta, E R R \gamma$ and probably ERR $\beta$ activate miR-208b and miR-499 triggering a Type I fiber program while PPAR $\alpha$ suppresses the program. The effect of exercise could stimulate this program via the transcriptional coactivator PGC- $1 \alpha$.

receptor-miRNA networks involved in the coordinated regulation of metabolic and structural programs in muscle. Future studies aimed at targeting the PPAR $\beta / \delta, \operatorname{ERR} \gamma$ and miR-499 components of the circuit will be of interest. Of note, nuclear receptors form the second largest class of drug targets, with an estimated share of $10 \%-15 \%$ of the global pharmaceutical market. In addition, direct manipulation of miR-499 levels in muscle through biological approaches is also warranted. We are optimistic that one day a trained effect can be attained without exercise training by taking an "exercise pill".

We thank members of Dr. Gan's laboratory for advice and support. Work in Dr. Gan's laboratory was supported by the Model Animal Research Center of Nanjing University Start Fund and the Jiangsu Natural Science Foundation (BK20140600).

1 Schiaffino S, Reggiani C. Fiber types in mammalian skeletal muscles. Physiol Rev, 2011, 91: 1447-1531

2 Zierath JR, Hawley JA. Skeletal muscle fiber type: influence on contractile and metabolic properties. PLoS Biol, 2004, 2: e348

3 Saltin B, Henriksson J, Nygaard E, Andersen P, Jansson E. Fiber types and metabolic potentials of skeletal muscles in sedentary man and endurance runners. Ann N Y Acad Sci, 1977, 301: 3-29

4 Holloszy JO, Coyle EF. Adaptations of skeletal muscle to endurance exercise and their metabolic consequences. J Appl Physiol, 1984, 56: 831-838

5 Yan Z, Okutsu M, Akhtar YN, Lira VA. Regulation of exerciseinduced fiber type transformation, mitochondrial biogenesis, and 
angiogenesis in skeletal muscle. J Appl Physiol (1985), 2011, 110: 264-274

6 Pette D, Staron RS. Myosin isoforms, muscle fiber types, and transitions. Microsc Res Tech, 2000, 50: 500-509

7 Lillioja S, Young AA, Culter CL, Ivy JL, Abbott WG, Zawadzki JK, Yki-Jarvinen H, Christin L, Secomb TW, Bogardus C. Skeletal muscle capillary density and fiber type are possible determinants of in vivo insulin resistance in man. J Clin Invest, 1987, 80: 415-424

8 Bassel-Duby R, Olson EN. Signaling pathways in skeletal muscle remodeling. Ann Rev Biochem, 2006, 75: 19-37

9 Potthoff MJ, Wu H, Arnold MA, Shelton JM, Backs J, McAnally J, Richardson JA, Bassel-Duby R, Olson EN. Histone deacetylase degradation and MEF2 activation promote the formation of slow-twitch myofibers. J Clin Invest, 2007, 117: 2459-2467

10 Desvergne B, Wahli W. Peroxisome proliferator-activated receptors: nuclear control of metabolism. Endocrine Rev, 1999, 20: 649-688

11 Hong SH, Ahmadian M, Yu RT, Atkins AR, Downes M, Evans RM. Nuclear receptors and metabolism: from feast to famine. Diabetologia, 2014, 57: 860-867

12 Fan W, Atkins AR, Yu RT, Downes M, Evans RM. Road to exercise mimetics: targeting nuclear receptors in skeletal muscle. J Mol Endocrinol, 2013, 51: T87-100

13 Madrazo JA, Kelly DP. The PPAR trio: regulators of myocardial energy metabolism in health and disease. J Mol Cell Cardiol, 2008, 44: 968-975

14 Lefebvre P, Chinetti G, Fruchart JC, Staels B. Sorting out the roles of PPAR alpha in energy metabolism and vascular homeostasis. J Clin Invest, 2006, 116: 571-580

15 Gulick T, Cresci S, Caira T, Moore DD, Kelly DP. The peroxisome proliferator-activated receptor regulates mitochondrial fatty acid oxidative enzyme gene expression. Proc Natl Acad Sci USA, 1994, 91: 11012-11016

16 Barish GD, Narkar VA, Evans RM. PPAR delta: a dagger in the heart of the metabolic syndrome. J Clin Invest, 2006, 116: 590-597

17 Nielsen R, Pedersen TA, Hagenbeek D, Moulos P, Siersbaek R, Megens E, Denissov S, Borgesen M, Francoijs KJ, Mandrup S, Stunnenberg HG. Genome-wide profiling of PPARgamma:RXR and RNA polymerase II occupancy reveals temporal activation of distinct metabolic pathways and changes in RXR dimer composition during adipogenesis. Genes Dev, 2008, 22: 2953-2967

18 Finck BN, Bernal-Mizrachi C, Han DH, Coleman T, Sambandam N, LaRiviere LL, Holloszy JO, Semenkovich CF, Kelly DP. A potential link between muscle peroxisome proliferator-activated receptor-alpha signaling and obesity-related diabetes. Cell Metab, 2005, 1: 133-144

19 Gan Z, Burkart-Hartman EM, Han DH, Finck B, Leone TC, Smith EY, Ayala JE, Holloszy J, Kelly DP. The nuclear receptor PPARbeta/delta programs muscle glucose metabolism in cooperation with AMPK and MEF2. Genes Dev, 2011, 25: 2619-2630

20 Gan Z, Rumsey J, Hazen BC, Lai L, Leone TC, Vega RB, Xie H, Conley KE, Auwerx J, Smith SR, Olson EN, Kralli A, Kelly DP. Nuclear receptor/microRNA circuitry links muscle fiber type to energy metabolism. J Clin Invest, 2013, 123: 2564-2575

21 Leone TC, Weinheimer CJ, Kelly DP. A critical role for the peroxisome proliferator-activated receptor alpha (PPARalpha) in the cellular fasting response: the PPARalpha-null mouse as a model of fatty acid oxidation disorders. Proc Natl Acad Sci USA, 1999, 96: 7473-7478

22 Burkart EM, Sambandam N, Han X, Gross RW, Courtois M, Gierasch CM, Shoghi K, Welch MJ, Kelly DP. Nuclear receptors PPARbeta/delta and PPARalpha direct distinct metabolic regulatory programs in the mouse heart. J Clin Invest, 2007, 117: 3930-3939

23 Narkar VA, Downes M, Yu RT, Embler E, Wang YX, Banayo E, Mihaylova MM, Nelson MC, Zou Y, Juguilon H, Kang H, Shaw RJ, Evans RM. AMPK and PPARdelta agonists are exercise mimetics. Cell, 2008, 134: 405-415

24 Luquet S, Lopez-Soriano J, Holst D, Fredenrich A, Melki J, Rassoulzadegan M, Grimaldi PA. Peroxisome proliferator-activated receptor delta controls muscle development and oxidative capability. FASEB J, 2003, 17: 2299-2301
25 Wang YX, Zhang CL, Yu RT, Cho HK, Nelson MC, Bayuga-Ocampo CR, Ham J, Kang H, Evans RM. Regulation of muscle fiber type and running endurance by PPARdelta. PLoS Biol, 2004, 2: e294

26 Schuler M, Ali F, Chambon C, Duteil D, Bornert JM, Tardivel A, Desvergne B, Wahli W, Chambon P, Metzger D. PGC1alpha expression is controlled in skeletal muscles by PPARbeta, whose ablation results in fiber-type switching, obesity, and type 2 diabetes. Cell Metab, 2006, 4: 407-414

27 Puigserver P, Wu Z, Park CW, Graves R, Wright M, Spiegelman BM. A cold-inducible coactivator of nuclear receptors linked to adaptive thermogenesis. Cell, 1998, 92: 829-839

28 Wu Z, Puigserver P, Andersson U, Zhang C, Adelmant G, Mootha V, Troy A, Cinti S, Lowell B, Scarpulla RC, Spiegelman BM. Mechanisms controlling mitochondrial biogenesis and respiration through the thermogenic coactivator PGC-1. Cell, 1999, 98: 115-124

29 Handschin C, Spiegelman BM. Peroxisome proliferator-activated receptor gamma coactivator 1 coactivators, energy homeostasis, and metabolism. Endocrine Rev, 2006, 27: 728-735

30 Puigserver P, Spiegelman BM. Peroxisome proliferator-activated receptor-gamma coactivator 1 alpha (PGC-1 alpha): transcriptional coactivator and metabolic regulator. Endocrine Rev, 2003, 24: 78-90

31 Kelly DP, Scarpulla RC. Transcriptional regulatory circuits controlling mitochondrial biogenesis and function. Genes Dev, 2004, 18: $357-368$

32 Finck BN, Kelly DP. PGC-1 coactivators: inducible regulators of energy metabolism in health and disease. J Clin Invest, 2006, 116: 615-622

33 Lelliott CJ, Medina-Gomez G, Petrovic N, Kis A, Feldmann HM, Bjursell M, Parker N, Curtis K, Campbell M, Hu P, Zhang D, Litwin SE, Zaha VG, Fountain KT, Boudina S, Jimenez-Linan M, Blount M, Lopez M, Meirhaeghe A, Bohlooly YM, Storlien L, Stromstedt M, Snaith M, Oresic M, Abel ED, Cannon B, Vidal-Puig A. Ablation of PGC-1beta results in defective mitochondrial activity, thermogenesis, hepatic function, and cardiac performance. PLoS Biol, 2006, 4: e369

34 Sonoda J, Mehl IR, Chong LW, Nofsinger RR, Evans RM. PGC-1beta controls mitochondrial metabolism to modulate circadian activity, adaptive thermogenesis, and hepatic steatosis. Proc Natl Acad Sci USA, 2007, 104: 5223-5228

35 Vega RB, Huss JM, Kelly DP. The coactivator PGC-1 cooperates with peroxisome proliferator-activated receptor alpha in transcriptional control of nuclear genes encoding mitochondrial fatty acid oxidation enzymes. Mol Cell Biol, 2000, 20: 1868-1876

36 Pilegaard H, Saltin B, Neufer PD. Exercise induces transient transcriptional activation of the PGC-1alpha gene in human skeletal muscle. J Physiol, 2003, 546: 851-858

37 Vianna CR, Huntgeburth M, Coppari R, Choi CS, Lin J, Krauss S, Barbatelli G, Tzameli I, Kim YB, Cinti S, Shulman GI, Spiegelman BM, Lowell BB. Hypomorphic mutation of PGC-1beta causes mitochondrial dysfunction and liver insulin resistance. Cell Metab, 2006, 4: 453-464

38 Russell LK, Mansfield CM, Lehman JJ, Kovacs A, Courtois M, Saffitz JE, Medeiros DM, Valencik ML, McDonald JA, Kelly DP. Cardiac-specific induction of the transcriptional coactivator peroxisome proliferator-activated receptor gamma coactivator-1alpha promotes mitochondrial biogenesis and reversible cardiomyopathy in a developmental stage-dependent manner. Circulat Res, 2004, 94: 525-533

39 Zechner C, Lai L, Zechner JF, Geng T, Yan Z, Rumsey JW, Collia D, Chen Z, Wozniak DF, Leone TC, Kelly DP. Total skeletal muscle PGC-1 deficiency uncouples mitochondrial derangements from fiber type determination and insulin sensitivity. Cell Metab, 2010, 12: 633-642

40 Goto M, Terada S, Kato M, Katoh M, Yokozeki T, Tabata I, Shimokawa T. cDNA cloning and mRNA analysis of PGC-1 in epitrochlearis muscle in swimming-exercised rats. Biochem Biophys Res Commun, 2000, 274: 350-354

41 Baar K, Wende AR, Jones TE, Marison M, Nolte LA, Chen M, Kelly DP, Holloszy JO. Adaptations of skeletal muscle to exercise: rapid 
increase in the transcriptional coactivator PGC-1. FASEB J, 2002, 16: 1879-1886

42 Lehman JJ, Barger PM, Kovacs A, Saffitz JE, Medeiros DM, Kelly DP. Peroxisome proliferator-activated receptor gamma coactivator-1 promotes cardiac mitochondrial biogenesis. J Clin Invest, 2000, 106: $847-856$

43 Lin J, Wu H, Tarr PT, Zhang CY, Wu Z, Boss O, Michael LF, Puigserver P, Isotani E, Olson EN, Lowell BB, Bassel-Duby R, Spiegelman BM. Transcriptional co-activator PGC-1 alpha drives the formation of slow-twitch muscle fibres. Nature, 2002, 418: 797-801

44 Wende AR, Schaeffer PJ, Parker GJ, Zechner C, Han DH, Chen MM, Hancock CR, Lehman JJ, Huss JM, McClain DA, Holloszy JO, Kelly DP. A role for the transcriptional coactivator PGC-1alpha in muscle refueling. J Biol Chem, 2007, 282: 36642-36651

45 Lin J, Wu PH, Tarr PT, Lindenberg KS, St-Pierre J, Zhang CY, Mootha VK, Jager S, Vianna CR, Reznick RM, Cui L, Manieri M, Donovan MX, Wu Z, Cooper MP, Fan MC, Rohas LM, Zavacki AM, Cinti S, Shulman GI, Lowell BB, Krainc D, Spiegelman BM. Defects in adaptive energy metabolism with CNS-linked hyperactivity in PGC-1alpha null mice. Cell, 2004, 119: 121-135

46 Arany Z, He H, Lin J, Hoyer K, Handschin C, Toka O, Ahmad F, Matsui T, Chin S, Wu PH, Rybkin, II, Shelton JM, Manieri M, Cinti $\mathrm{S}$, Schoen FJ, Bassel-Duby R, Rosenzweig A, Ingwall JS, Spiegelman BM. Transcriptional coactivator PGC-1 alpha controls the energy state and contractile function of cardiac muscle. Cell Metab, 2005, 1: 259-271

47 Handschin C, Chin S, Li P, Liu F, Maratos-Flier E, Lebrasseur NK, Yan Z, Spiegelman BM. Skeletal muscle fiber-type switching, exercise intolerance, and myopathy in PGC-1alpha muscle-specific knock-out animals. J Biol Chem, 2007, 282: 30014-30021

48 Leone TC, Lehman JJ, Finck BN, Schaeffer PJ, Wende AR, Boudina S, Courtois M, Wozniak DF, Sambandam N, Bernal-Mizrachi C, Chen Z, Holloszy JO, Medeiros DM, Schmidt RE, Saffitz JE, Abel ED, Semenkovich CF, Kelly DP. PGC-1alpha deficiency causes multi-system energy metabolic derangements: muscle dysfunction, abnormal weight control and hepatic steatosis. PLoS Biol, 2005, 3: e101

49 Ruas JL, White JP, Rao RR, Kleiner S, Brannan KT, Harrison BC, Greene NP, Wu J, Estall JL, Irving BA, Lanza IR, Rasbach KA, Okutsu M, Nair KS, Yan Z, Leinwand LA, Spiegelman BM. A PGC-1 $\alpha$ isoform induced by resistance training regulates skeletal muscle hypertrophy. Cell, 2012, 151: 1319-1331

50 Agudelo LZ, Femenia T, Orhan F, Porsmyr-Palmertz M, Goiny M, Martinez-Redondo V, Correia JC, Izadi M, Bhat M, SchuppeKoistinen I, Pettersson AT, Ferreira DM, Krook A, Barres R, Zierath JR, Erhardt S, Lindskog M, Ruas JL. Skeletal muscle PGC-1alpha1 modulates kynurenine metabolism and mediates resilience to stress-induced depression. Cell, 2014, 159: 33-45

51 Lai L, Leone TC, Zechner C, Schaeffer PJ, Kelly SM, Flanagan DP, Medeiros DM, Kovacs A, Kelly DP. Transcriptional coactivators PGC-1alpha and PGC-lbeta control overlapping programs required for perinatal maturation of the heart. Genes Dev, 2008, 22: 1948-1961

52 Bartel DP. MicroRNAs: target recognition and regulatory functions. Cell, 2009, 136: 215-233

53 Mendell JT, Olson EN. MicroRNAs in stress signaling and human disease. Cell, 2012, 148: 1172-1187

54 Williams AH, Liu N, van Rooij E, Olson EN. MicroRNA control of muscle development and disease. Curr Opin Cell Biol, 2009, 21:
461-469

55 Guttman M, Rinn JL. Modular regulatory principles of large non-coding RNAs. Nature, 2012, 482: 339-346

56 Small EM, Olson EN. Pervasive roles of microRNAs in cardiovascular biology. Nature, 2011, 469: 336-342

57 Song X, Shan D, Chen J, Jing Q. miRNAs and lncRNAs in vascular injury and remodeling. Sci China Life Sci, 2014, 57: 826-835

58 Lee RC, Feinbaum RL, Ambros V. The C. elegans heterochronic gene lin-4 encodes small RNAs with antisense complementarity to lin-14. Cell, 1993, 75: 843-854

59 Wightman B, Ha I, Ruvkun G. Posttranscriptional regulation of the heterochronic gene lin-14 by lin-4 mediates temporal pattern formation in C. elegans. Cell, 1993, 75: 855-862

60 Reinhart BJ, Weinstein EG, Rhoades MW, Bartel B, Bartel DP. MicroRNAs in plants. Genes Dev, 2002, 16: 1616-1626

61 Lagos-Quintana M, Rauhut R, Lendeckel W, Tuschl T. Identification of novel genes coding for small expressed RNAs. Science, 2001, 294 : $853-858$

62 Lau NC, Lim LP, Weinstein EG, Bartel DP. An abundant class of tiny RNAs with probable regulatory roles in Caenorhabditis elegans. Science, 2001, 294: 858-862

63 Matkovich SJ, Hu Y, Eschenbacher WH, Dorn LE, Dorn GW, 2nd. Direct and indirect involvement of microRNA-499 in clinical and experimental cardiomyopathy. Circulat Res, 2012, 111: 521-531

64 Chen K, Rajewsky N. The evolution of gene regulation by transcription factors and microRNAs. Nat Rev Genet, 2007, 8: 93-103

65 van Rooij E, Quiat D, Johnson BA, Sutherland LB, Qi X, Richardson JA, Kelm RJ, Jr., Olson EN. A family of microRNAs encoded by myosin genes governs myosin expression and muscle performance. Dev Cell, 2009, 17: 662-673

66 Chen JF, Callis TE, Wang DZ. microRNAs and muscle disorders. J Cell Sci, 2009, 122: 13-20

67 van Rooij E, Liu N, Olson EN. MicroRNAs flex their muscles. Trends Genet, 2008, 24: 159-166

68 Bell ML, Buvoli M, Leinwand LA. Uncoupling of expression of an intronic microRNA and its myosin host gene by exon skipping. Mol Cell Biol, 2010, 30: 1937-1945

69 Ji J, Tsika GL, Rindt H, Schreiber KL, McCarthy JJ, Kelm RJ, Jr., Tsika R. Puralpha and Purbeta collaborate with Sp3 to negatively regulate beta-myosin heavy chain gene expression during skeletal muscle inactivity. Mol Cell Biol, 2007, 27: 1531-1543

70 Hagiwara N, Yeh M, Liu A. Sox6 is required for normal fiber type differentiation of fetal skeletal muscle in mice. Dev Dynam, 2007, 236: 2062-2076

71 von Hofsten J, Elworthy S, Gilchrist MJ, Smith JC, Wardle FC, Ingham PW. Prdm1- and Sox6-mediated transcriptional repression specifies muscle fibre type in the zebrafish embryo. EMBO Rep, 2008, 9: 683-689

72 Quiat D, Voelker KA, Pei J, Grishin NV, Grange RW, Bassel-Duby $\mathrm{R}$, Olson EN. Concerted regulation of myofiber-specific gene expression and muscle performance by the transcriptional repressor Sox6. Proc Natl Acad Sci USA, 2011, 108: 10196-10201

73 Narkar VA, Fan W, Downes M, Yu RT, Jonker JW, Alaynick WA, Banayo E, Karunasiri MS, Lorca S, Evans RM. Exercise and PGC1alpha-independent synchronization of type I muscle metabolism and vasculature by ERRgamma. Cell Metab, 2011, 13: 283-293

74 Yan J, Zhao Y, Zhao B. Green tea catechins prevent obesity through modulation of peroxisome proliferator-activated receptors. Sci China Life Sci, 2013, 56: 804-810

Open Access This article is distributed under the terms of the Creative Commons Attribution License which permits any use, distribution, and reproduction in any medium, provided the original author(s) and source are credited. 